Errera, M. \& Greenstein, J. P. (1948). J. nat. Cancer Inst. 8, 71.

Falconer, J. S. \& Taylor, D. B. (1946). Biochem. J. 40, 831.

Fodor, P. (1946). Nature, Lond., 158, 375.

Gerhardt, C. (1853). Liebigs Ann. 87, 149.

Kobezen, M. J., Metcalf, R. L. \& Fuhuto, T. R. (1954). J. agric. Food Chem. 2, 864.

Löwenstein, E. (1930). Dtsch. med. Wschr. 56, 1010.

Meister, A., Levintow, L., Greenfield, R. E. \& Abendschein, P. A. (1955). J. biol. Chem. 215, 441.

Mendel, B., Myers, D. K., Uyldert, I. E., Ruys, A. C. \& de Bruyn, W. M. (1953). Brit. J. Pharmacol. 8, 217.

Michel, H. O., Bernheim, F. \& Bernheim, M. L. C. (1937). J. Pharmacol. 61, 321.

Murray, D. R. P. \& King, C. G. (1930). Biochem. J. 24, 190. Myers, D. K. (1956). Biochem. J. 64, 740.

Myers, D. K. \& Mendel, B. (1953). Biochem. J. 53, 16.

Myers, D. K., Schotte, A., Boer, H. \& Borsje-Bakker, H. (1955). Biochem. J. 61, 521.
Neurath, H. \& Schwert, G. W. (1950). Chem. Rev. 46, 69.

Proskauer, B. \& Beck, M. (1894). Z. Hyg. InfektKr. 18, 128.

Roulet, F. \& Zeller, E. A. (1945). Experientia, 1, 122.

Roulet, F. \& Zeller, E. A. (1948). Helv. chim. acta, 31, 1915.

Ruys, A. C. (1954). Leeuwenhoek ned. Tijdschr. 20, 145.

Schroeter, G. (1909). Ber. dtsch. chem. Ges. 42, 3356.

Schwert, G. W. \& Glaid, A. J. (1952). J.biol. Chem. 199, 613.

Smith, E. L. (1951a). Advanc. Enzymol. 12, 191.

Smith, E. L. (1951 b). In The Enzymes, vol. 1, part 2, p. 793. Ed. by Sumner, J. B. \& Myrbäck, K. New York: Academic Press.

Smith, E. L. \& Spackman, D. H. (1955). J. biol. Chem. 212, 271.

Sobotka, H. \& Glick, D. (1934). J. biol. Chem. 105, 199.

Wislicenus, W. (1897). Liebigs Ann. 296, 361.

Youmans, G. P. \& Karlson, A. G. (1947). Amer. Rev. Tuberc. 55, 529.

\title{
Studies on Ali-esterases
}

\section{SELECTIVE INHIBITORS OF THE ESTERASES OF BRAIN AND SAPROPHYTIC MYCOBACTERIA*}

\author{
BY D. K. MYERS, $\dagger$ A. KEMP JUN., JUSTINA W. TOL AND MARIA H. T. DE JONGE \\ Pharmaco-therapeutic Laboratory, University of Amsterdam, Amsterdam, Holland
}

(Received 26 June 1956)

Previous investigations have shown that the growth of Mycobacterium tuberculosis and certain strains of saprophytic mycobacteria can be prevented in vitro by certain organophosphorus compounds (Mendel, Myers, Uyldert, Ruys \& de Bruyn, 1953; Ruys, 1954 ; Myers, Tol \& de Jonge, 1957); it was suggested that the effect of these compounds on growth may be related to their ability to inhibit the ali-esterases of these mycobacteria. The organophosphorus compounds which were used in these experiments cannot be used for the same purpose in vivo since they are also potent inhibitors of true cholinesterase and are consequently highly toxic to animals. In an attempt to find more selective inhibitors of the ali-esterases, a series of compounds was synthesized and tested initially against the true cholinesterase and ali-esterase of rat brain. Some of the results obtained in these preliminary experiments have been reported previously (Myers, Mendel, Gersmann \& Ketelaar, 1952; Mendel et al. 1953; Myers, 1953, 1954 ; Myers \& Kemp, 1954).

In the present work a number of new inhibitory compounds were prepared and investigated as inhibitors of the ali-esterases of the saprophytic

* Part 5: Myers, Tol \& de Jonge (1957).

$\dagger$ Present address: Suffield Experimental Station, Ralston, Alberta, Canada. mycobacteria and of the esterases of rat brain in vitro. The results obtained appear to offer valuable information concerning the factors which govern the selectivity of these inhibitors towards a given esterase.

\section{EXPERIMENTAL}

Determination of esterase activity. Esterase activity was measured by a manometric method in the Warburg apparatus at $37.5^{\circ}$ and $\mathrm{pH} 7.4$ in a medium containing $0.025 \mathrm{M}-\mathrm{NaHCO}_{3}$ and saturated with $\mathrm{CO}_{2}+\mathrm{N}_{2}(5: 95, \mathrm{v} / \mathrm{v})$. The reaction mixture was incubated for $30 \mathrm{~min}$. at $37.5^{\circ}$, with or without added inhibitor, before adding a small volume of substrate to determine the residual esterase activity. The ali-esterase activities were measured with $0.2 \%(w / v)$ of tributyrin as substrate and the true cholinesterase activity of rat brain with $0.03 \mathrm{M}$ acetyl- $\beta$-methylcholine. All values were corrected for the very slow spontaneous hydrolysis of the substrate in question under the same experimental conditions.

The enzyme preparations used were described in previous publications (Myers, 1956b; Myers et al. 1957); for comparative purposes, we have tested the true cholinesterase and ali-esterase of rat-brain homogenates, and the aliesterases of five strains of saprophytic mycobacteria. Two of these strains, Mycobacterium phlei and Myco. B, are not affected by the organophosphorus compounds in their growth at $37^{\circ}$ in the medium of Dubos \& Davis (1946), even though the ali-esterase activity is inhibited (Myers et al. 1957); the growth of the other three strains, which were 
designated as Myco. C, D and E, is readily inhibited under the same conditions (Myers et al. 1957). It might be noted that the hydrolysis of tributyrin by $M y c o$. C, D and E seems to be due to a single esterase and the hydrolysis of acetyl- $\beta$ methylcholine by rat-brain suspensions is, of course, also due to a single enzyme, the true cholinesterase. In the other cases, it was possible to distinguish more than one esterase in the preparation capable of hydrolysing tributyrin by the use of diisopropyl $p$-nitrophenyl phosphate (DINP) and phenyl $N$ - $n$-propylcarbamate as selective inhibitors (Myers, 1956b; Myers et al. 1957). For purposes of convenience in the execution of the experiments, we have only considered the esterase in each preparation which is responsible for the major portion of the activity towards tributyrin. Thus the experiments reported below are concerned with the 'DINP-sensitive' esterase of rat brain (cf. Myers, 1956b), the 'carbamate-resistant' or 'DINPsensitive' esterase of Myco. phlei, and the 'carbamate sensitive' esterase of $M y c o$. B ; these esterases are responsible for approximately 70,92 and $80 \%$ respectively of the total activity of each preparation towards tributyrin.

Under these circumstances, the molar concentration of inhibitor required to produce $50 \%$ inhibition of the esterase $\left(I_{50}\right)$ could be readily estimated from the graphs relating the concentration of inhibitor to the percentage inhibition of the esterase activity (cf. Myers et al. 1957). The results were expressed as the negative logarithm of the $I_{50}$ value $\left(\mathrm{p} I_{50}\right)$. The $\mathrm{p} I_{50}$ value was found to be reproducible to within 0.1 unit in duplicate experiments carried out at different times over a period of several months.

Inhibitors. The inhibitors used in these experiments are listed in Table 1. Compounds 1 (tetraethyl pyrophosphate, TEPP), 6 and 18 were supplied by Dr H. R. Gersmann, Laboratory of General and Inorganic Chemistry, University of Amsterdam. Compound 2 (diisopropyl phosphorofluoridate, DFP) was obtained from Dr B. C. Saunders, Cambridge University, England; compound 3 (Mipafox, Isopestox) from Dr G. S. Hartley, Pest Control Ltd., England; compounds 9 (diethyl $p$-nitrophenyl phosphate, E600, Paraoxon) and 10 (diisopropyl $p$-nitrophenyl phosphate, DINP) from Mr B. Topley, Albright and Wilson Ltd., England; compounds 12 (Ro3-0620) and 29 (Ro3-0717) from Dr A. L. Morrison, Roche Products Ltd., Welwyn Garden City, England; compound 37 ( $N N$-diethylcarbamoyl fluoride) from Dr G. Schrader, Elberfeld, Germany; and compound 49 (Ro2-3510) from Dr J. A. Aeschlimann, Hoffmann-La Roche Inc., Nutley, N.J., U.S.A. Most of these compounds are described in Kosolapoff (1950) and Schrader (1952).

The remaining compounds were synthesized in this laboratory; the melting points are uncorrected. Compounds 4 (m.p. $144^{\circ}$ ) and 5 (m.p. 168-170 ) are described by Cook et al. (1949) and were prepared by the same methods. Compound 8 was prepared by the method described by Cebrian (1951) and compound 7 (m.p. 81-83 ${ }^{\circ}$ ) was prepared in the same way with $p$-nitrophenyl phosphorodichloridate and methylamine. Compound 11 (m.p. $154-156^{\circ}$ ) is described by Ketelaar \& Gersmann (1950).

The following compounds were prepared from sodium $p$ nitrophenoxide and the corresponding phosphoryl chloride derivative in dioxan, by the techniques described by Ketelaar \& Gersmann (1950) for the synthesis and purification of compounds 11 and 18; the phosphoryl chloride derivatives are described in the literature cited below.
Compound 13 (m.p. 117-118 ${ }^{\circ}$ ) was prepared from sodium $p$-nitrophenoxide and $O N$-diphenyl phosphoramidochloridate (Michaelis, 1903); compound 14 (m.p. 178-179 ${ }^{\circ}$ ) from the chloride listed as compound 5 (Cook et al. 1949); compound 15 (m.p. 113-114 ${ }^{\circ}$ ) from phenyl phosphorodichloridate (Freeman \& Colver, 1938); compound 16 (m.p. $175-176^{\circ}$ ) from $N$-phenylphosphoramidic dichloride (Michaelis \& Schulze, 1893); compound 17 (m.p. 147 ${ }^{\circ}$ ) from benzylphosphonic dichloride (Kinnear \& Perren, 1952); compound 20 (m.p. $135-137^{\circ}$ ) from $N$-methylphosphoramidic dichloride (Michaelis, 1903); compound 21 (m.p.118 ${ }^{\circ}$ ) from chloromethylphosphonic dichloride (Kinnear \& Perren, 1952); compound 22 (m.p. $155^{\circ}$ ) from ethylphosphonic dichloride (Kinnear \& Perren, 1952); compound 23 (m.p. $148^{\circ}$ ) from $N N$-dimethylphosphoramidic dichloride (Michaelis, 1903); compound 24 (m.p. 112 ) from $\alpha \alpha$ dichloromethylphosphonic dichloride (Kinnear \& Perren, 1952); compound 25 (m.p. 93-94 ${ }^{\circ}$ ) from isopropylphosphonic dichloride (Kinnear \& Perren, 1952); compound 26 (m.p. $130-131^{\circ}$ ) from cyclohexylphosphonic dichloride (Graf, 1952); and compound 27 (m.p. $103^{\circ}$ ) from phenylphosphonic dichloride (Michaelis \& Kammerer, 1875). The identity of all of these compounds was confirmed by the constant melting points obtained after successive recrystallizations and by determinations of the amount of $p$-nitrophenol liberated by hydrolysis in alkali.

Compound 19 (m.p. $107^{\circ}$ ) was prepared from the corresponding phosphorothioate (Ketelaar \& Gersmann, 1950) by isomerization at $140^{\circ}$ as described by Myers et al. (1952); compound 28 was prepared in the same way from the corresponding phosphorothioate which was supplied under the designation E1907 by Dr G. Schrader, Elberfeld, Germany (cf. Mendel et al. 1953). Compounds 30 (m.p. 92-93 ${ }^{\circ}$ ), 31 (m.p. $93^{\circ}$ ) and 32 (m.p. 105 $)$ were prepared in dioxan from $N$-methylphosphoramidic dichloride (Michaelis, 1903) with the sodium salts of $p$-chlorophenol, phenol and $p$-cresol respectively. Compound 33 (m.p. $154-155^{\circ}$ ) was prepared by the method of Autenrieth (1897) and compound 34 (b.p. $250^{\circ}$ at $20 \mathrm{~mm}$.) by the method of Michaelis \& Kaehne (1898).

The two sulphonyl fluoride derivatives (compounds 35 and 36) were prepared previously (Myers \& Kemp, 1954) by the method of Davies \& Dick (1932). $N$-Phenylcarbamoyl fluoride (compound 38; m.p. 30-31 ${ }^{\circ}$ ) is described by Buckley, Piggot \& Welch (1945). Most of the remaining carbamate derivatives (compound 39, m.p. 127-129 ; compound 40, m.p. $113-114^{\circ}$; compound 41, m.p. $147-148^{\circ}$; compound 43 , m.p. $46-47^{\circ}$; compound 44 , m.p. $85-86^{\circ}$; compound 45 , m.p. $97^{\circ}$; compound 46, m.p. 116-117 ; compound 47, m.p. $88-89^{\circ}$; compound 48 , m.p. $157-159^{\circ}$ ) are described by Kobezen, Metcalf \& Fuhuto (1954). Phenyl $N$ - $n$-propylcarbamate (compound 42, m.p. 53-54') was prepared in the same way from phenol and $n$-propyl isocyanate (cf. Myers et al. 1957).

Many of these inhibitors are sparingly soluble in water and consequently the stock solutions of inhibitor were prepared with acetone. The final concentration of acetone in the reaction mixture with the enzyme preparations was usually $1 \%(v / v)$. In these cases, the activity of the enzyme plus inhibitor was compared with the activity of the uninhibited enzyme in a control vessel containing the same amount of acetone. However, the concentration of acetone used had little or no effect on the esterase activity of the uninhibited enzyme. 
Table 1. Inhibitory activity of various compounds towards the esterases of brain and of mycobacteria

Determination of the inhibitory activity of these compounds is described in the text. $\mathrm{p} I_{50}$ is the negative logarithm of the molar concentration of inhibitor required to produced $50 \%$ inhibition of the esterase activity after incubation for $30 \mathrm{~min}$. at $37 \cdot 5^{\circ}$ and $\mathrm{pH} \mathrm{7.4}$. The following abbreviations are used in writing the formulae of the inhibitory compounds: Me-, methyl; Et-, ethyl; $\mathrm{Pr}$-, $n$-propyl; isoPr-, isopropyl; $\mathrm{Ph}$-, phenyl; cycloHx-, cyclohexyl; $\mathrm{Ph}$-CHz-, benzyl; $p$-Me-Ph-, $p$-cresyl; $p$-Cl-Ph-, $p$-chlorophenyl; $o$-Cl-Ph-, o-chlorophenyl; $p$-NO $\mathrm{N}_{2}-\mathrm{Ph}$-, $p$-nitrophenyl.

Compound no. Structural formula

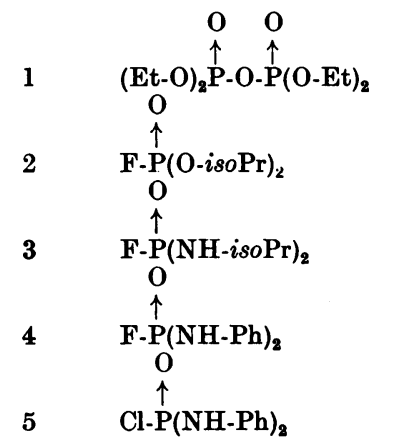

6

$7 \quad p$ - $\mathrm{NO}_{2}-\mathrm{Ph}-\mathrm{O}-\mathrm{P}(\mathrm{NH}-\mathrm{Me})_{2}$ $\uparrow$

$8 \quad p-\mathrm{NO}_{2}-\mathrm{Ph}-\mathrm{O}-\mathrm{P}(\mathrm{O}-\mathrm{Me})_{2}$ 0
$\uparrow$

$9 \quad p-\mathrm{NO}_{2}-\mathrm{Ph}-\mathrm{O}-\mathrm{P}(\mathrm{O}-\mathrm{Et})_{2}$

$10 p-\mathrm{NO}_{2}-\mathrm{Ph}-\mathrm{O}-\mathrm{P}(\mathrm{O}-i s o \mathrm{Pr})_{2}$ 0

$11 p-\mathrm{NO}_{2}-\mathrm{Ph}-\mathrm{O}-\mathrm{P}\left(\mathrm{O}-\mathrm{Ph}-\mathrm{NO}_{2}-p\right)_{2}$

12

$13 p$ - $\mathrm{NO}_{2}-\mathrm{Ph}-\mathrm{O}-\mathrm{P}-\mathrm{O}-\mathrm{Ph}$

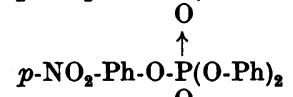<smiles>[O]</smiles><smiles>[3H][V]</smiles><smiles>CNc1ccccc1</smiles>

$14 p-p-\mathrm{NO}_{2}-\mathrm{Ph}-\mathrm{O} \cdot \mathrm{P}(\mathrm{NH}-\mathrm{Ph})_{2}$ 0

$15 \quad\left(p-\mathrm{NO}_{2}-\mathrm{Ph}-\mathrm{O}\right)_{2} \mathrm{P}-\mathrm{O}-\mathrm{Ph}$

16

17 $\mathrm{p} I_{50}$ values with the following ali-esterases

\begin{tabular}{|c|c|c|c|c|c|}
\hline & \multirow{2}{*}{$\begin{array}{l}\text { with the true } \\
\text { cholinesterase } \\
\text { of rat brain }\end{array}$} \\
\hline $\begin{array}{l}\text { Rat } \\
\text { brain }\end{array}$ & $\begin{array}{l}\text { Myco. } \\
\text { phlei }\end{array}$ & $\underset{\text { B }}{\text { Myco. }}$ & $\underset{\mathbf{D}}{\text { Myco. }}$ & $\underset{\mathbf{E}}{\text { Myco. }}$ & \\
\hline 5.9 & $7 \cdot 8$ & 4.9 & $4 \cdot 8$ & $4 \cdot 7$ & $8 \cdot 2$ \\
\hline $5 \cdot 1$ & 6.9 & 4.9 & $5 \cdot 5$ & $5 \cdot 8$ & $6 \cdot 7$ \\
\hline $4 \cdot 2$ & $6 \cdot 0$ & $3 \cdot 8$ & $5 \cdot 4$ & $5 \cdot 6$ & $3 \cdot 5$ \\
\hline $4 \cdot 3$ & $4 \cdot 7$ & $4 \cdot 0$ & 4.9 & $5 \cdot 1$ & $4 \cdot 8$ \\
\hline $3 \cdot 1$ & $3 \cdot 6$ & $3 \cdot 4$ & $3 \cdot 8$ & $3 \cdot 8$ & $2 \cdot 4$ \\
\hline $5 \cdot 0$ & $5 \cdot 3$ & - & $3 \cdot 0$ & - & $4 \cdot 4$ \\
\hline 5.9 & $6 \cdot 2$ & $4 \cdot 8$ & $4 \cdot 0$ & $4 \cdot 0$ & $4 \cdot 2$ \\
\hline $6 \cdot 6$ & $7 \cdot 1$ & $5 \cdot 0$ & $6 \cdot 1$ & $6 \cdot 3$ & $7 \cdot 7$ \\
\hline $7 \cdot 4$ & $7 \cdot 8$ & 6.8 & $7 \cdot 0$ & $7 \cdot 0$ & 8.0 \\
\hline $7 \cdot 3$ & $7 \cdot 2$ & $5 \cdot 5$ & $6 \cdot 1$ & $6 \cdot 2$ & $7 \cdot 3$ \\
\hline $4 \cdot 8$ & $6 \cdot 0$ & $5 \cdot 0$ & $5 \cdot 0$ & $5 \cdot 1$ & $4 \cdot 4$ \\
\hline $7 \cdot 2$ & $6 \cdot 7$ & $5 \cdot 3$ & 6.9 & $7 \cdot 1$ & 6.3 \\
\hline 6.5 & $6 \cdot 1$ & $4 \cdot 8$ & $5 \cdot 4$ & $5 \cdot 7$ & $3 \cdot 5$ \\
\hline 6.4 & $6 \cdot 2$ & $5 \cdot 4$ & $5 \cdot 6$ & $5 \cdot 9$ & 3.9 \\
\hline 6.9 & $6 \cdot 7$ & $5 \cdot 3$ & $6 \cdot 0$ & $6 \cdot 1$ & $6 \cdot 0$ \\
\hline 6.4 & $6 \cdot 2$ & $5 \cdot 8$ & $6 \cdot 0$ & $6 \cdot 0$ & $4 \cdot 7$ \\
\hline $7 \cdot 3$ & 6.5 & $7 \cdot 1$ & $7 \cdot 7$ & 7.5 & $5 \cdot 1$ \\
\hline
\end{tabular}


Table 1 (cont.)

Compound
no.

Structural formula

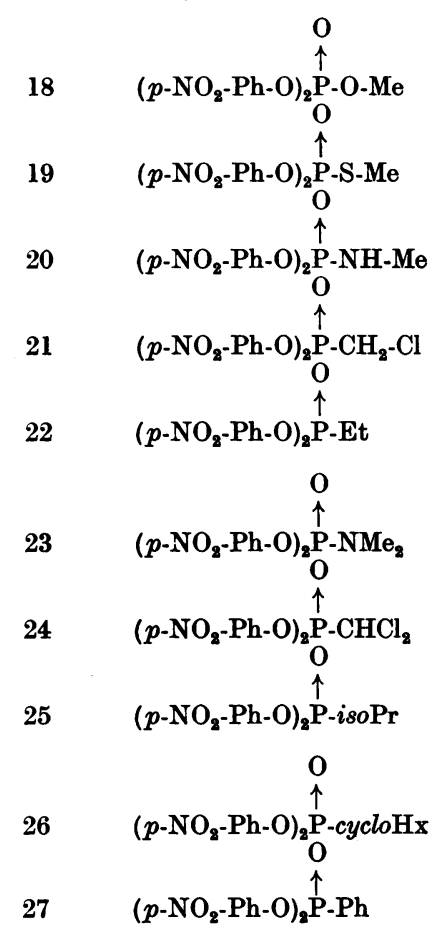

$28 \quad$ (EtO.OC-Ph-O) ${ }_{2}^{\stackrel{P}{\uparrow}-\mathrm{S}-\mathrm{Me}}$

$29 \quad(\mathrm{MeO} . \mathrm{OC}-\mathrm{Ph}-\mathrm{O})_{\mathbf{2}} \stackrel{\uparrow}{\mathrm{P}-\mathrm{NH}}-\mathrm{Me}$

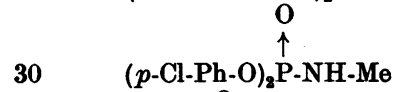

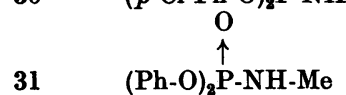

$32 \quad \begin{gathered}\mathrm{O} \\ \uparrow \\ \mathrm{O}\end{gathered}$

$33 \quad(p \text {-Cl-Ph-O })_{2}{ }_{2} \mathbf{P}-\mathrm{NH}_{2}$

$34 \quad(p \text {-Cl-Ph-O })_{2}{ }_{2} \mathrm{P}-\mathrm{Me}$

$35 \quad \mathrm{~F}-\mathrm{SO}_{2}-\mathrm{Me}$

$36 \quad \mathrm{~F}-\mathrm{SO}_{2}-\mathrm{CH}_{2}-\mathrm{Cl}$

$37 \quad$ F-C-NEt

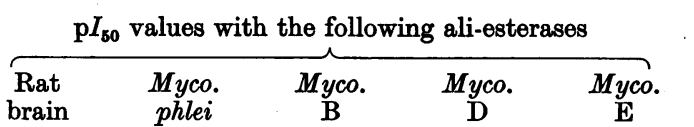

$\mathrm{p} I_{50}$ value with the true cholinesterase of rat brain$$
6 \cdot 9
$$$$
7 \cdot 6
$$$$
6.9
$$$$
5 \cdot 3
$$$$
7 \cdot 4
$$

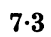

$6 \cdot 8$

$5 \cdot 3$

$5 \cdot 1$

$4 \cdot 9$

7.7

$7 \cdot 2$

6.9

$5 \cdot 6$

$5 \cdot 4$

5・3

$7 \cdot 4$

$7 \cdot 2$

$6 \cdot 6$

$5 \cdot 7$

5.5

5.1

$7 \cdot 5$

$7 \cdot 8$

$6 \cdot 7$

$5 \cdot 8$

$5 \cdot 7$

6.0

$5 \cdot 6$

6.7

$4 \cdot 9$

$4 \cdot 6$

$4 \cdot 4$

5.0

$5 \cdot 6$

6.6

$4 \cdot 9$

4.9

4.9

5.1

$5 \cdot 7$

6.9

$\mathbf{4} \cdot 7$

4.5

$4 \cdot 4$

3.9

$4 \cdot 8$

$7 \cdot 2$

$6 \cdot 2$

6.0

6.0

$(<3 \cdot 0)$

$5 \cdot 4$

$7 \cdot 7$

6.0

5.7

5.7

6.3

$6 \cdot 3$

$7 \cdot 2$

6.5

5.3

5.0

5.0

$7 \cdot 6$

$6 \cdot 7$

$5 \cdot 2$

5.0

4.8

$5 \cdot 4$

$6 \cdot 2$

6.1

4.0

4.1

4.1

(ca. 3)

$5 \cdot 2$

$\mathbf{4 \cdot 5}$

$3 \cdot 2$

$2 \cdot 5$

$2 \cdot 6$

3.2

$4 \cdot 5$

$3 \cdot 4$

(ca. 2.5)

$(<2 \cdot 5)$

$(<2 \cdot 5)$

$(<2 \cdot 5)$

5.9

6.3

5.4

$5 \cdot 4$

5.3

4.6

4.3

5.7

$4 \cdot 8$

$4 \cdot 7$

4.7

3.0

3.8

3.8

3.6

3.8

4.0

6.2

4.9

5.3

5.6

6. 0

6.3

4.4

5.3

5.5

5.0

3.1

1.9

$2 \cdot 2$

$2 \cdot 9$

2.7

3.2 
Table 1 (cont.)

\begin{tabular}{|c|c|c|c|c|c|c|c|}
\hline \multirow[b]{2}{*}{$\begin{array}{l}\text { Compound } \\
\text { no. }\end{array}$} & \multirow[b]{2}{*}{ Structural formula } & & \multirow{2}{*}{$\begin{array}{l}\text { with the true } \\
\text { cholinesterase } \\
\text { of rat brain }\end{array}$} \\
\hline & & $\begin{array}{c}\text { Rat } \\
\text { brain }\end{array}$ & $\begin{array}{l}\text { Myco. } \\
\text { phlei }\end{array}$ & $\underset{\mathrm{B}}{M y c o .}$ & Myco. & $\underset{\mathbf{E}}{\mathbf{M y c o}}$ & \\
\hline 39 & Ph-O-C-NH-Ph & $2 \cdot 8$ & $2 \cdot 7$ & $3 \cdot 9$ & $5 \cdot 7$ & $5 \cdot 6$ & $2 \cdot 8$ \\
\hline 40 & $p$-Me-Ph-O-C-NH-Ph & $3 \cdot 4$ & $2 \cdot 4$ & $3 \cdot 7$ & $6 \cdot 0$ & $5 \cdot 9$ & $3 \cdot 2$ \\
\hline 41 & $p$-Cl-Ph-O-C-NH-Ph & $3 \cdot 7$ & $3 \cdot 8$ & $4 \cdot 4$ & $5 \cdot 9$ & $5 \cdot 8$ & $(<3)$ \\
\hline 42 & Ph-O-C-NH-Pr & $2 \cdot 6$ & $4 \cdot 5$ & $7 \cdot 0$ & $8 \cdot 1$ & $8 \cdot 0$ & $(c a .2 \cdot 3)$ \\
\hline 43 & $\begin{array}{c}\mathrm{Ph}-\mathrm{O}-\mathrm{C}-\mathrm{NH}-\mathrm{Et} \\
\mathrm{O}\end{array}$ & $2 \cdot 8$ & $3 \cdot 7$ & $5 \cdot 8$ & $7 \cdot 1$ & $7 \cdot 0$ & $2 \cdot 8$ \\
\hline 44 & Ph-O-C-NH-Me & $\mathbf{3} \cdot \mathbf{1}$ & $3 \cdot 2$ & 4.5 & $6 \cdot 0$ & $6 \cdot 0$ & $4 \cdot 0$ \\
\hline 45 & $p$-Me-Ph-O-C-NH-Me & $3 \cdot 5$ & $3 \cdot 0$ & $4 \cdot 2$ & $5 \cdot 8$ & $5 \cdot 8$ & $4 \cdot 2$ \\
\hline 46 & $p$-Cl-Ph-O-C-NH-Me & $\mathbf{3} \cdot \mathbf{8}$ & $3 \cdot 9$ & $4 \cdot 7$ & $6 \cdot 1$ & $6 \cdot 1$ & $3 \cdot 9$ \\
\hline $\mathbf{4 7}$ & $o-\mathrm{Cl}-\mathrm{Ph}-\mathrm{O}-\mathrm{C}-\mathrm{NH}-\mathrm{Me}$ & 3.9 & $4 \cdot 0$ & $4 \cdot 8$ & $6 \cdot 7$ & $6 \cdot 7$ & $5 \cdot 3$ \\
\hline 48 & $p-\mathrm{NO}_{2}-\mathrm{Ph}-\mathrm{O}-\mathrm{C}-\mathrm{NH}-\mathrm{Me}$ & $3 \cdot 5$ & $3 \cdot 4$ & $4 \cdot 2$ & $4 \cdot 8$ & $4 \cdot 8$ & $3 \cdot 4$ \\
\hline 49 & $p-\mathrm{NO}_{2}-\mathrm{Ph}-\mathrm{O}-\mathrm{C}-\mathrm{NMe}_{2}$ & $3 \cdot 9$ & $4 \cdot 7$ & $4 \cdot 3$ & $4 \cdot 8$ & $4 \cdot 8$ & $3 \cdot 9$ \\
\hline
\end{tabular}

\section{RESULTS}

The results obtained are summarized in Table 1. The characteristics of the esterases in question have been described in previous investigations (Myers, $1956 b$; Myers et al. 1957); data on the rate of hydrolysis, dipole moments and absorption spectra of many of the organophosphorus compounds are given by Ketelaar, Gersmann \& Koopmans (1952) and by Gersmann (1956). Data on the rate of hydrolysis of the carbamate esters are given by Kobezen et al. (1954).

Owing to the complicated nature of the esterases present, we have not studied the effects of the inhibitors listed with the strain of saprophytic mycobacteria which was designated as $M y c o$. A in the previous investigation (Myers et al. 1957). However, it was observed that neither of the esterases present in Myco. A was very sensitive to inhibition by compound 26 ; in this respect, these esterases differ from the esterases of the other mycobacteria shown in Table 1.

Table 1 does not include the results obtained with the strain designated as Myco. C. As noted pre- viously, the ali-esterase of $M y c o . C$ is very similar to the esterases of Myco. D and E (Myers et.al. 1957); this conclusion was confirmed in the present investigation. $\mathrm{p} I_{50}$ values were determined with Myco. C for the compounds 7, 9, 10, 12, 17, 19, 20, $26,27,39,42,43$ and 44 . In no case did the $\mathrm{p} I_{50}$ value with $M y c o$. C differ by more than 0.3 unit from the average of the $\mathrm{p} I_{50}$ values given in Table 1 for Myco. D and E. As can be seen from Table 1, the $p I_{50}$ values obtained with $M y c o . D$ and $E$ are nearly identical in most instances and seldom differ by more than 0.2 unit from each other.

The results given for the DINP-sensitive aliesterase of rat brain are slightly different from those reported for some of the inhibitors in earlier publications, owing to the fact that the presence of more than one ali-esterase in the brain was not taken into consideration previously. When only that portion of the total activity which is due to the DINP. sensitive esterase (i.e. 70\%) is considered, most of the $\mathrm{p} I_{50}$ values become slightly greater than those estimated on the basis of the total ali-esterase activity towards tributyrin. However, the necessary corrections in the $\mathrm{p} I_{50}$ values do not amount to 
more than $0 \cdot 2-0 \cdot 3$ unit. This correction is somewhat uncertain in all cases since it is based on the shape of the curves obtained when the percentage inhibition of the esterase activity is plotted against the logarithm of the molar concentration of inhibitor. Nevertheless, these differences are of minor significance in comparison with the much greater differences between the $\mathrm{p} I_{50}$ values for different types of esterases (see Table 1).

\section{DISCUSSION}

The original purpose of the present investigation was to find a compound which would act as a selective inhibitor of the ali-esterases in general without inhibiting the cholinesterases, in the same way that eserine and prostigmine selectively inhibit the cholinesterases without inhibiting the aliesterases (cf. Easson \& Stedman, 1937; Richter \& Croft, 1942; Mendel \& Rudney, 1943). We have not been able to find an inhibitor of this type, possibly owing to the fact that the group of enzymes designated as ali-esterases includes a wide variety of different types of esterase. However, the results obtained do indicate some of the factors which govern the selectivity towards a given esterase.

In the first place, it might be noted that the carbamate-resistant ali-esterase of Myco. phlei is readily inhibited by most of the organophosphorus compounds listed in Table 1. The first two compounds, TEPP and DFP, which have been extensively studied in connexion with their inhibitory activity against the cholinesterases, are potent inhibitors of the ali-esterase of liver (Webb, 1948; Wilson, Levine \& Freiberger, 1952; Myers \& Mendel, 1953). However, these compounds have considerably less activity against the ali-esterases of brain and of the saprophytic mycobacteria with the exception of Myco. phlei (Table 1). The esterase of $M y c o$. phlei would, in this respect, appear to be more closely related to the ali-esterase (B-type esterase) of liver than the ali-esterases of the other mycobacteria; a similar conclusion was reached from a study of the substrate specificity of these esterases (Myers et al. 1957). The reason for the rapid inhibition of the ali-esterases of liver and Myco. phlei by organophosphorus compounds is not known; however, it is to be expected that most, if not all, of the organophosphorus compounds which may be used as selective inhibitors of other ali-esterases will also inhibit the esterases of $M y c o$. phlei and of liver.

The selection of inhibitors for study by previous investigators has been based largely on the toxicity of the compound and its inhibitory activity against the cholinesterases. To obtain a selective inhibitor of an ali-esterase it was necessary to search for reactive compounds which might have a low inhibitory activity towards the true cholinesterase.
For this purpose we were interested in determining the extent to which the same factors govern the activity of the inhibitor against the ali-esterase and the cholinesterase.

The inhibition of the true cholinesterase by organophosphorus compounds has been formulated as a reaction of the type

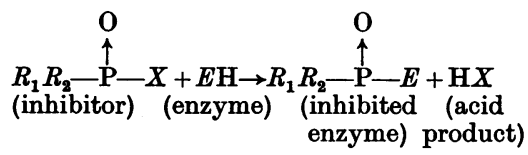

which involves a primary attack by a group in the active centre of the enzyme on the electrophilic phosphorus atom of the inhibitor (cf. Burgen \& Hobbiger, 1951; Wilson, 1951; Aldridge, 1953b). An analogous reaction mechanism has been suggested for the inhibition of esterases by sulphonyl and carbamoyl fluorides (Myers \& Kemp, 1954; Myers, $1956 a$ ), and the reaction with the substrate also follows the same general pattern (Nachmansohn \& Wilson, 1951).

Aldridge \& Davison $(1952 a, b)$ and others have concluded that the rate at which the true cholinesterase is inhibited by the members of a homologous series of organophosphorus compounds parallels the reactivity of the $\mathrm{P}-X$ bond. In a series of diethyl phenyl phosphate derivatives, the effect of various substituents on the phenyl ring in increasing the inhibitory activity was found to be proportional to their effect in increasing the rate of spontaneous hydrolysis of the $\mathrm{P}-X$ bond in aqueous solution (Aldridge \& Davison, 1952a). This relationship has been confirmed with other substituents (Myers, 1954) and seems to hold for all of the aliesterases tested in the present investigation as well as for the true cholinesterase. The inhibitory activity of the series of $N$-methyl diphenylphosphoramidates with different substituents in the para position on the phenyl rings increases in the order expected, i.e. $\mathrm{CH}_{3}<\mathrm{H}<\mathrm{Cl}<\mathrm{CO} . \mathrm{OCH}_{3} \leqslant \mathrm{NO}_{2}$ (Table 1, compounds 32, 31, 30, 29 and 20 respectively).

Other $X$ groups did not appear to offer any advantage over the $p$-nitrophenyl group in our search for selective inhibitors of the ali-esterases. Substitution of fluoride for the $p$-nitrophenyl group (compounds 2 and 10 respectively) decreased the inhibitory activity slightly without appreciably affecting the selectivity towards the mycobacterial esterases (Table 1). The single chloro derivative tested (compound 5) was considerably less active than the corresponding fluoro derivative (compound 4); most of the other phosphoryl chloride derivatives are too rapidly hydrolysed in aqueous solutions to be of any value as esterase inhibitors. The pyrophosphate derivative (compound 1) was considerably less active against most of the ali-esterases and 
more selective for the true cholinesterase than was the corresponding $p$-nitrophenyl derivative (compound 9). The effect of anionic and cationic substituents in the benzene ring in place of the nitro group has been discussed previously (Myers, 1953, 1954; cf. Wilson et al. 1952); these substituents did not appear to offer any advantages in the present investigation. Consequently, most of the remaining organophosphorus derivatives tested contained a $p$-nitrophenyl group.

However, in studying the effect of alterations in the $R$ groups, it was frequently more convenient to synthesize compounds containing two $p$-nitrophenyl groups; one of these can be regarded as the $X$ group and the other, therefore, as an $R$ group in the general formula indicated above. The rate of spontaneous hydrolysis of the $\mathrm{P}-X$ bond in aqueous solution increases markedly when a second and third $p$-nitrophenyl group is introduced into the phosphate ester (cf. Ketelaar et al. 1952). However, the apparent inhibitory activity of the compound does not increase proportionately (Table 1). In fact, the inhibitory activity seems to decrease considerably when the third $p$-nitrophenyl group is introduced (compound 11). Aldridge \& Davison (1952b) encountered a similar anomaly in their series of compounds when the lability of the inhibitor was altered by other means than by an alteration in the substituent on the benzene ring of the $X$ group, e.g. when the $S$-p-nitrophenyl group was substituted for the $p$-nitrophenyl group in $\mathrm{E} 600$. One of the factors contributing to these anomalies may be the fact that the compound is rapidly destroyed in the aqueous reaction mixture before it has time to inhibit the esterases. Under these conditions, the apparent $\mathrm{p} I_{50}$ value which is measured would be too low; however, this factor should not affect the selectivity of the inhibitor towards the various esterases.

The character of the $R$ groups has a marked influence on the selectivity of the inhibitor. Aldridge (1953a) has presented evidence in support of the theory that the size and shape of the $R$ groups have a similar influence on the selectivity of the inhibitor towards the cholinesterases and on the rate of hydrolysis of choline esters by the same enzyme. However, it might be noted that the rate of hydrolysis of choline esters by the true cholinesterase is probably limited by the rate of hydrolysis of the acyl residue from the active centre of the enzyme (Wilson, 1952; cf. Myers, 1954; SuzuokiZiro \& Suzuoki-Tuneko, 1954); this reaction is analogous to the reversal of inhibition by hydrolysis of the phosphorylated derivative of the enzyme (cf. Aldridge, 1953b) and is directly opposed to the process of inhibition. Moreover, the data given by Aldridge (1953a) show much greater alterations in the selectivity when the type of $R$ group is altered than when the size is altered. The same factor was emphasized by the results obtained in the present investigation (Table 1). For example, a comparison of the results given for compounds 2 and 3, which are approximately isosteric, shows that the selectivity towards all of the ali-esterases is increased markedly when the isopropoxy groups of DFP are replaced by isopropylamido groups. The inhibitory activity towards the true cholinesterase decreases markedly, whereas the inhibitory activity towards the ali-esterases only shows a slight decrease when the oxygen atoms adjacent to the phosphorus are replaced by less electronegative nitrogen atoms (Table 1). Although steric factors must have an important influence on the selectivity of an inhibitor, it appears that alterations in the electronic pattern may have a greater influence. It will therefore be difficult to interpret the influence of steric factors on the selectivity of these inhibitors.

However, if we compare the results obtained with various organophosphorus compounds which are approximately isosteric, it becomes evident that alterations in the electronic pattern have less influence on the inhibitory activity towards the aliesterases than on the inhibitory activity towards the true cholinesterase. This was noted with compounds 2 and 3 above and is also apparent from the results presented in Table 1 for compounds 18-22, compounds $23-25$ and compounds 26 and 27 . The results obtained with compounds 7 and 8 and compounds 11-17, in which more than one $R$ group is varied, also show a tendency in the same direction but are less consistent. In most cases, the members of each series of isosteric compounds all exhibit approximately the same inhibitory activity towards a given ali-esterase, whereas the inhibitory activity towards the true cholinesterase varies over a considerable range.

The selectivity of these inhibitors towards the true cholinesterase usually decreases in the following order: $\quad\left(R_{2}=\right) \quad R-\mathrm{O}-, \quad R-\mathrm{S}-, \quad R-\mathrm{NH}-=R-\mathrm{CH}_{2}-$ (Table 1). The electronegative character of these groups, i.e. their ability to attract electrons from the phosphorus atom to which they are attached, decreases in the same order (cf. Johnson, 1942). The influence of this inductive effect of the $R$ group is even more striking in compounds 26 and 27 in which $R_{2}$ is a cyclohexane and a benzene ring respectively. Both compounds inhibit the ali-esterases to about the same extent, but compound 27 is at least 2000 times more active than compound 26 against the true cholinesterase (Table 1). In this connexion it should be noted that the effect of the $R$ group on the selectivity of the inhibitor towards the true cholinesterase probably reflects the polarizability of the $\mathrm{P}-R$ bond during the reaction with the cholinesterase as well as the permanent polarization which is induced in this bond. 
The results discussed above agree well with the theory of cholinesterase inhibition outlined by Wilson (1951), but it is necessary to assume that the inhibition of the ali-esterases follows a different reaction mechanism. Undoubtedly the inhibitory reaction with the ali-esterases also involves the formation of a phosphorylated derivative of the active centre of the enzyme since the inhibitory activity of the organophosphorus compounds is highly dependent on the lability of the $\mathrm{P}-X$ bond as noted above; moreover, the inhibition is practically irreversible in certain cases (cf. Mendel \& Myers, 1953) and phosphorylserine derivatives have been isolated from a preparation of inhibited ali-esterase as well as from inhibited cholinesterase (Cohen, Oosterbaan \& Warringa, 1955). However, it seems unlikely that the inhibitory reaction with the aliesterases involves a primary attack by a neutrophilic group in the enzyme on the phosphorus atom of the inhibitor, as postulated for the true cholinesterase.

It might be noted that the results reported by Aldridge (1953a) for the selectivity of inhibitors towards true cholinesterase as compared with pseudocholinesterase tend to follow the same general pattern as the results reported in Table 1 . This would suggest that the mechanism of the reaction between the organophosphorus compounds and pseudocholinesterase may be similar to that with the aliesterases. Ormerod (1953) has suggested that the reaction between the substrate and pseudocholinesterase involves a primary attack on the oxygen atom of the carbonyl group. A similar type of reaction between the enzyme and the oxygen atom of the phosphoryl group of the organophosphorus compounds would provide a possible explanation for the above results.

Consideration of the results obtained with compounds 39-41 and 45-49 indicates that the true cholinesterase must be inhibited in a different way by these carbamate esters. The experimental evidence obtained previously showed that the inhibition of the pseudocholinesterase by a prostigmine analogue (Myers, 1952) and of both the cholinesterase and ali-esterase by two carbamoyl fluorides (Myers, 1956a) is analogous to the inhibition by the organophosphorus compounds, i.e. the inhibitory reaction involves the formation of a dialkylcarbamoyl derivative of the active centre of the enzyme. However, Kobezen et al. (1954) concluded that the inhibition of true cholinesterase by the carbamate esters shown in Table 1 is due to the combination of the intact ester with the enzyme. Our results confirm this conclusion. The inhibitory activity of the $N$-methylcarbamoyl esters listed as compounds 44-48 towards the true cholinesterase decreases in the order $p$-cresyl, phenyl, $p$-chlorophenyl, $p$-nitrophenyl (Table 1). This order is the reverse of that expected if the inhibitory reaction involved a transesterification of the $N$-methylcarbamoyl group from the phenol to the active centre and is the reverse of that observed with analogous organophosphorus compounds. Moreover, the inhibitory activity of all of these compounds towards the true cholinesterase is relatively low; this would agree with the supposition that the inhibition is due to an adsorption of the intact molecule on the enzyme.

Surprisingly, these carbamate esters were found to be much more active against certain of the aliesterases (Table 1). The explanation of this finding is still uncertain, and further investigation will be required to ascertain the mechanism of this inhibition. It might be noted that these compounds are almost isosteric with the phenyl esters which are rapidly hydrolysed by the ali-esterases (cf. Myers, $1956 b$; Myers et al. 1957). However, the carbamate derivatives are relatively stable compounds (Kobezen et al. 1954); our own results indicate that the rate of spontaneous hydrolysis of $p$-nitrophenyl $N N$-dimethylcarbamate (compound 49) in aqueous solution at $\mathrm{pH} 8.6$ is approximately 15000 times slower than the rate of hydrolysis of $p$-nitrophenyl acetate under the same conditions (Myers, 1954). It would be expected therefore that the carbamate esters would be also hydrolysed extremely slowly by the esterases.

The behaviour of the sulphonyl derivatives seems to be analogous to that of the corresponding carbamoyl derivatives. The sulphonyl fluorides, like the carbamoyl fluorides, exhibit a moderate inhibitory activity towards the cholinesterase and ali-esterases (Table 1) (cf. Myers \& Kemp, 1954). However, the $p$-nitrophenyl ester of methanesulphonic acid is practically inactive against the esterases of rat brain (Myers, 1954); this behaviour resembles that of the $p$-nitrophenyl carbamate derivatives and contrasts with that of the $p$-nitrophenyl phosphate derivatives. The reason for this difference is not known but must be attributed to differences in the structure of the inhibitor and the mechanism of the inhibition rather than differences in the reactivity of the inhibitor. The ratio of the rates of spontaneous hydrolysis in aqueous solution at $\mathrm{pH} 8.6$ is approximately $40: 20: 1$ for the $p$ nitrophenyl esters of diethyl phosphoric acid (compound 9), methanesulphonic acid and $N N$. dimethylcarbamic acid (compound 49) respectively (Myers, 1954). If one could extrapolate the data of Aldridge \& Davison $(1952 a, b)$ from the phosphate esters to include the two last compounds, the ratio of the $I_{50}$ values should show the same relation as the ratio of the rates of spontaneous hydrolysis; actually the ratio of the $I_{50}$ values measured with the true cholinesterase of rat brain is approximately $10^{6}: 1: 100$ for the three compounds mentioned above. 
Although many of the results given in Table 1 still retain an empirical character, a number of the compounds listed appear to be valuable as selective inhibitors of the ali-esterases. Compounds 13, 14 and 17 inhibit all of the ali-esterases more strongly than the true cholinesterase, but the activity of compounds 13 and 14 is not very high. Compounds 19-21 are all selective inhibitors of the particular ali-esterases studied in brain and Myco. phlei but do not exhibit a similar selectivity towards the aliesterases of Myco. D and E. Compound 26 is exceptionally selective in its inhibitory activity towards the ali-esterases of the mycobacteria; however, the large branched alkyl group which is attached to the phosphorus atom does not appear to be favourable for inhibition of the brain esterase. If the inhibition of the ali-esterases by organophosphorus compounds does not depend on the inductive effects of the $R$ groups as was suggested above, then the effect of the $R$ groups on the selectivity of the inhibitor towards one ali-esterase as compared with another (rather than with the true cholinesterase) should depend mainly on steric factors. It would appear that the inhibitory activity of the organophosphorus compounds towards the ali-esterases of Myco. D and $\mathrm{E}$ is not favoured by a small $R$ group as in compounds 19-25; this result does not parallel the substrate specificity patterns observed previously (Myers et al. 1957).

In addition to the organophosphorus compounds mentioned above, Table 1 includes a series of carbamate esters which could be used as selective inhibitors of the ali-esterases of Myco. D and E. The most promising member of the limited series of compounds tested in the present investigation would appear to be phenyl $N$-propylcarbamate (compound 42). These carbamate esters differ from the organophosphorus compounds in that they do not exhibit any appreciable inhibitory activity towards the type of ali-esterase found in rat brain and only exhibit a moderate activity against the liver ali-esterase (cf. Myers et al. 1957).

There is always a possibility that complications would be encountered in the application of these selective inhibitors in experiments in vivo. For example, the compound might be altered in the animal body into a derivative which exhibits a different inhibitory activity and possibly a different selectivity. This type of alteration has been observed repeatedly in previous investigations. However, preliminary experiments did not reveal any significant degree of inhibition of the cholinesterases after injection of the compounds 26 and 42. Moreover, we have been successful in producing a selective inhibition of the ali-esterase of rat brain in vivo after injection of compounds 19 (Myers et al. 1952), 13 (Myers, 1954), 17, 21 and 26 (unpublished experiments).

\section{SUMMARY}

1. A series of organophosphorus compounds and carbamate esters has been investigated in connexion with their inhibitory activity towards the esterases of rat brain and of saprophytic mycobacteria in vitro.

2. The factors affecting the inhibitory activity and selectivity of these compounds have been discussed and correlated with the differences in the mechanism of the inhibitory reaction. Although many of the compounds investigated are poor inhibitors of true cholinesterase, they may be highly active against ali-esterases.

The authors are much indebted to Professor B. Mendel for suggesting this problem and for his continued interest in the progress of the investigation.

\section{REFERENCES}

Aldridge, W. N. (1953a). Biochem. J. 53, 62.

Aldridge, W. N. (1953b). Biochem. J. 54, 442.

Aldridge, W. N. \& Davison, A. N. (1952a). Biochem. J. 51, 62.

Aldridge, W. N. \& Davison, A. N. (1952b). Biochem. J. 52, 663.

Autenrieth, W. (1897). Ber. dtsch. chem. Ges. 30, 2369.

Buckley, G. D., Piggot, A. \& Welch, A. J. E. (1945). J. chem. Soc. p. 864.

Burgen, A. S. V. \& Hobbiger, F. (1951). Brit. J. Pharmacol. 6, 593.

Cebrian, R. G. (1951). Ann. real. Soc. Espan. fis. quim. B, 47, 841.

Cohen, J. A., Oosterbaan, R. A. \& Warringa, M. G. P. J. (1955). Biochim. biophys. Acta, 18, 228.

Cook, H. G., Ilett, J. D., Saunders, B. C., Stacey, G. J., Watson, H. G., Wilding, I. G. E. \& Woodcock, S. J. (1949). J. chem. Soc. p. 2921.

Davies, W. \& Dick, J. H. (1932). J. chem. Soc. p. 483.

Dubos, R. J. \& Davis, B. D. (1946). J. exp. Med. 83, 409.

Easson, L. H. \& Stedman, E. (1937). Biochem. J. 31, 1723.

Freeman, H. F. \& Colver, C. W. (1938). J. Amer. chem. Soc. 60, 750.

Gersmann, H. R. (1956). Ph.D. Thesis: University of Amsterdam.

Graf, R. (1952). Ber. dtsch. chem. Ges. 85, 9.

Johnson, J. R. (1942). In Organic Chemistry, vol. 2, p. 1821. Ed. by Gilman, H. New York: John Wiley and Sons, Inc.

Ketelaar, J. A. A. \& Gersmann, H. R. (1950). J. Amer. chem. Soc. 72, 5777.

Ketelaar, J. A. A., Gersmann, H. R. \& Koopmans, K. (1952). Rec. Trav. chim. Pays-Bas, 71, 1253.

Kinnear, A. M. \& Perren, E. A. (1952). J. chem. Soc. p. 3437.

Kobezen, M. J., Metcalf, R. L. \& Fuhuto, T. R. (1954). J. agric. Food Chem. 2, 864.

Kosolapoff, G. M. (1950). Organophosphorus Compounds. New York: John Wiley and Sons, Inc.

Mendel, B. \& Myers, D. K. (1953). Biochem. J. 53, xvi.

Mendel, B., Myers, D. K., Uyldert, I. E., Ruys, A. C. \& de Bruyn, W. M. (1953). Brit. J. Pharmacol. 8, 217.

Mendel, B. \& Rudney, H. (1943). Biochem. J. 37, 59.

Michaelis, A. (1903). Liebigs Ann. 326, 129. 
Michaelis, A. \& Kaehne, R. (1898). Ber.dtsch. chem. Ges. 31, 1048.

Michaelis, A. \& Kammerer, F. (1875). Ber. dtsch. chem. Ges. 8, 1306.

Michaelis, A. \& Schulze, G. (1893). Ber. dtsch. chem. Ges. 26, 2937.

Myers, D. K. (1952). Biochem. J. 52, 46.

Myers, D. K. (1953). Acta physiol. pharm. néerl. 3, 136.

Myers, D. K. (1954). Ph.D. Thesis: University of Amsterdam.

Myers, D. K. (1956a). Biochem. J. 62, 556.

Myers, D. K. (1956b). Biochem. J. 64, 740.

Myers, D. K. \& Kemp, A. jun. (1954). Nature, Lond., 173, 33.

Myers, D. K. \& Mendel, B. (1953). Biochem. J. 53, 16.

Myers, D. K., Mendel, B., Gersmann, H. R. \& Ketelaar, J. A. A. (1952). Nature, Lond., 170, 805.
Myers, D. K., Tol, J. W. \& de Jonge, M. H. T. (1957). Biochem. J. 65, 223.

Nachmansohn, D. \& Wilson, I. B. (1951). Advanc. Enzymol. 12, 259.

Ormerod, W. E. (1953). Biochem. J. 54, 701.

Richter, D. \& Croft, P. G. (1942). Biochem. J. 36, 746.

Ruys, A. C. (1954). Leeuwenhoek ned. Tijdschr. 20, 145.

Schrader, G. (1952). Die Entwicklung neuer Insektizide auf Grundlage organischer Fluor- und Phosphor-verbindungen. Monogr. angew. Chem. 62. Wienheim/Bergstr.: Verlag Chemie.

Suzuoki-Ziro \& Suzuoki-Tuneko (1954). Nature, Lond., 173, 83.

Webb, E. C. (1948). Biochem. J. 42, 96.

Wilson, I. B. (1951). J. biol. Chem. 190, 111.

Wilson, I. B. (1952). J. biol. Chem. 197, 215.

Wilson, I. B., Levine, S. \& Freiberger, I. (1952). J. biol. Chem. 194, 613.

\title{
A Study of the Uptake of Silicon and Phosphorus by Wheat Plants, with Radiochemical Methods
}

\author{
By L. ROTHBUHR* AND F. SCOTT \\ Wolverhampton and Staffordshire Technical College, Wolverhampton
}

\section{(Received 29 October 1955)}

The limit of the classical gravimetric method for the determination of silicon is approximately 100 $1000 \mu \mathrm{g}$., weighed as silica. With the development of absorptiometric methods, which use either the yellow colour of the silicomolybdate complex or the blue colour obtained on reduction, the lower limit is approximately $10 \mu \mathrm{g}$. A recent paper by Miller \& Chalmers (1953) describes a sensitive microgravimetric method which is based on the precipitation of the quinoline salt of the heteromolybdate and gives a sensitivity of a few micrograms. The application of these methods in biological and medical investigations is somewhat restricted owing to the frequently encountered presence of phosphates, which form similar complexes with molybdate, and to the presence of other organic and inorganic substances which interfere with the methods. Though attempts have been made to overcome these difficulties, e.g. by bleaching the phosphate complex with citrate, oxalate or tartrate (Sesa \& Rogers, 1954a), adding excess of phosphate (Krummholz, 1933), or by extracting with organic solvents (Wadelin \& Mellon, 1953; Sesa \& Rogers, 1954b), the methods are not applicable to the exact determination of very small quantities of silicon in the form of silica or silicate.

Holt \& Yates (1953) have used radioactive silicon, ${ }^{31} \mathrm{Si}$, to determine the silicon content of organs in

* Permanent address: Max Planck Institut für Silikat. forschung, Zweigstelle Berlin. mice and rats by injecting the animals with active silicate solution and following the distribution in the body for a period of about $6 \mathrm{hr}$.

Previous work on the uptake of silicon by plants (Hull \& Morison, 1906; Jennings, 1919; Nemec, 1927; Whittenberger, 1945) deals with the absorption from soils by mature plants and the published figures only give a measure of the total silicon content in the later stages of development. It was hoped to show that silicon is readily absorbed in the very early stage of growth and to determine the rate of uptake over short intervals of time. It was also desirable to study the influence of added phosphate on the silica uptake.

There appears to be no published work in which radioactive silicon has been used to study the rate of silicon uptake by plants. Experiments are reported in this paper which show that it is possible to follow the uptake of silicon by wheat plants for at least $15 \mathrm{hr}$. by the use of radioactive silicon, even though the half-life of ${ }^{31} \mathrm{Si}$ is very short (157 min.) and the rate of uptake is comparatively small. The accuracy of the method is of the order of $0.5 \mu \mathrm{g}$. of silica $6 \mathrm{hr}$. after taking from the pile.

To facilitate comparison, experiments are described in which radioactive phosphorus is used to determine the rate of absorption of phosphate by similar plants, and to show the influence of added silicate on the phosphate uptake.

Bioch. 1957, 65 